\title{
ESTANISLAO ZULETA: EDUCACIÓN CON FILOSOFÍA
}

\author{
Oscar Pulido Cortés* \\ Universidad Pedagógica y Tecnológica de Colombia
}

\section{Resumen}

Este artículobusca presentar los rasgos fundamentales del pensamiento educativo del pensador colombiano Estanislao Zuleta, a través de su obra creadora.Seprocede a partir de un rastreo conceptual y discursivo de los textos publicados por el autor y de sus vivencias educativas, contadas principalmente en algunas entrevistas y testimonios. El texto está estructurado en dos partes: la primera presenta situaciones, escenas y datos relativos al autor en su contexto formativo, pues estas condiciones determinan sus apuestas sobre la educación en formas teóricas y prácticas; la segunda parte, presenta los principales aspectos del pensamiento educativo de Zuleta: el autodidactismo o la opción autónoma por el saber, el enseñar a pensar, la educación con filosofía y la educación para la democracia.

Palabras clave: Estanislao Zuleta, Filosofía de la educación, Autodidactismo, Educación filosófica.

\begin{abstract}
EstanislaoZuleta: education with philosophy. This article seeks to present the fundamental features of the educational thought of the Colombian thinker EstanislaoZuleta. We will begin with a conceptual and discursive tracking of the texts published by this author as well as his educational experiences, retrieved from a series of interviews and testimonies. The text is structured in two parts: the first presents situations, scenes and facts related to this author during his learning stage, due to the fact that these conditions will determine his main proposals regarding

* El artículo presenta algunos de los avances del proyecto denominado «Filosofías de la educación en Colombia» del grupo de investigación Filosofía, sociedad y educación. oscar.pulido@uptc.edu.co
\end{abstract}


education practice and theory. The second part presents the major aspects of Zuleta's educational thought: self-directed learning or the autonomous option of knowledge, teaching thinking, education with philosophy and education for democracy.

Key words: EstanislaoZuleta, philosophy of education, autodidacticism.

Creo que la Filosofía siempre que estuvo viva fue algo más que docencia y recuento de ideas. Fue vigilancia crítica, territorio del debate, impulso a la fecundidad del pensamiento. En nuestra sociedad el pensamiento está amenazado tanto por las formas de adaptación que se promueven, como por las formas de desadaptación que se producen. Si la Filosofía quiere llegar a ser importante, sino se conforma con un humilde sitio en la división social del trabajo, como especialización inocua en ideas generales, tiene que saberse combativa y afirmarse combatiente.

ZULETA, Estanislao. «Tribulación y felicidad del pensamiento».

\section{Introducción}

Estanislao Zuleta Velásquez se constituyó en un significativo intelectual del siglo XX para Colombia, hijo de una tradición intelectual familiar muy profunda. Participó de diversas maneras en la construcción de la nación colombiana con sus acciones de orden intelectual y político. Su trabajo intelectual impresionó por la comprensión y difusión de pensadores significativos en el mundo de la Filosofía, la Literatura, el Psicoanálisis, la Historia y la Sociología. De igual manera, tuvo participación como asesor de paz y fue cercano de algunos gobiernos colombianos. En el campo de la educación sugirió una particular forma de ver el fenómeno educativo y formativo, pues su discusión constante con el establecimiento y la institucionalización hizo posible una mirada distinta y muy contemporánea de las relaciones hombre-conocimiento.

\section{Sobre las condiciones de formación}

Estanislao Zuleta Velásquez (1935-1990) es uno de los pensadores colombianos más importante del siglo XX. Su amplio espectro académico, sus profundos análisis combinan la Filosofía, el Psicoanálisis, la Política, la Literatura, el Arte plástico y un capítulo especial: la educación. Aún este aspecto no se ha desarrollado suficientemente por sus comentaristas y estudiosos en sus planteamientos específicos y en sus 
prácticas contra las cuales Estanislao Zuleta realizó fuertes críticas, e incluso con su experiencia vital mostró otros caminos de lo educativo e incluso en lo pedagógico, aunque no es propiamente un teórico de lo educativo.

La vida de Zuleta es particularmente trágica en el sentido más nietzscheano del término, es decir, con incertidumbres frente a lo que se considera válido, enfrentar situaciones paradójicas y profundamente contradictorias ${ }^{1}$. Huérfano de padre a los cuatro meses de nacido, pues en aquel famoso accidente aéreo en Medellín en 1935 pereció su padreEstanislao Zuleta Ferrer y, además murieronalgunos personajes muy renombrados en la época entre ellos Ernesto Samper Mendoza, Guillermo Escobar Vélez, Jorge Moreno Olano y el cantante de tango argentino Carlos Gardel². Estanislao Zuleta Ferrer muere cuando tenía treinta años de edad y cumplía una muy importante carrera como intelectual y jurista, al lado de intelectuales de la talla de Fernando González llamado «El filósofo de Suramérica» quien, una vez se enteró de la muerte de su amigo, afirmó que «ahora ya no hay con quien hablar en este país» ${ }^{3}$ y Fernando Isaza, quien acompañará a Estanislao Zuleta hijo en muchas de sus empresas personales y académicas. La familia Zuleta, en su conjunto, provenía de la clase media alta de la provincia y de tradición académica e intelectual.

Margarita Velásquez, madre de Estanislao y viuda a muy temprana edad, nunca se recuperó de la ausencia de su esposo; en la formación de Estanislao y de su hermana estuvo siempre presente la figura mitificada y casi heroica de su padre. Estanislao tuvo un padre configurado por la narración. En esa narración había un ingrediente fundamental que era el desprecio por lo actual, por lo real, por lo presente, que obedecía a la negaciónde otro amor, de otro hombre, por parte de Margarita, pues ninguno pasaba la prueba de la confrontación con su maravilla irrecuperable. La influencia de la madre lleva a Estanislao a desarrollar una profunda pasión por lo narrado, lo vivido, el pasado durante la infancia, que luego explicitará en su obsesión por los libros encontrados a lo largo de su vida en las bibliotecas de su familia y luego en el mundo a académico con el cual se relacionó y que a su vez construyó a su alrededor. De esta manera, ante la ausencia del padre, Estanislao se crió entre

1 ZULETA, Estanislao.«La participación democrática en relación con la educación». En: BUSTAMANTE, G. et al. Estanislao Zuleta (1935-1990). Tunja: Ediciones La Rana y el Águila, 1990, p. 25.

2 MONTOYA, Ramiro. «Adolescencia de un memorioso». En: Al Margen. \# 23. Septiembre de 2007. Bogotá, p. 7.

3 ZULETA, José. «Semblanza». En: ZULETA, Estanislao.Colombia: Violencia, democracia y derechos humanos. Bogotá: Altamir Ediciones, 1991, p. 310. 
mujeres: su madre, sus tías, las niñeras. En alguna ocasión cita Ramiro Montoya Estanislao expresó "Yo no conocí padre, yo me crié entre mujeres» ${ }^{4}$; la única referencia paterna era su tío Fernando Isaza quien va a influir fuertemente en la formación académica del pensador y en algunas decisiones vitales.

La relación con la escuela y los procesos académicos formales fue problemática desde el comienzo. En una entrevista con Hernán Villa Garzón, Estanislao refiere:

Mis relaciones con la academia y con la escuela siempre fueron muy malas. Fui un pésimo estudiante. No recuerdo cuántos años perdí ni cuántos me regalaron, tengo la impresión de que los que no perdí me los regalaron. En realidad de esa época, hasta el cuarto de bachillerato en que me salí, son muy pocos los recuerdos buenos que tengo por el lado de los estudios. ${ }^{5}$

Esta narración de su tortuosa y desesperante experiencia con la escuela se evidenció desde la primaria, cuando sus maestros opinaban sobre él como un niño distraído, que no atendía y que se asfixiaba en clase, e incluso le recomendaron a Margarita su madre, que le realizará diferentes estudios médicos y psicológicos con los cuáles se pudiesen determinar sus comportamientos en la escuela. Los médicos de la época dictaminaron «que padecía asma y tal vez sufría una especie de retardo mental». ${ }^{6}$

Estanislao Zuleta no aguantó la escuela y cuando cursaba el hoy llamado grado noveno, en el liceo de la Universidad de Antioquia para la época cuarto de bachillerato, dejó la formalidad educativa, decisión que causó estupor en la familia con la que pensó iba a sufrir una ruptura profunda. El único que comprendió y apoyó la decisión de Estanislao fue su tío político y amigo Fernando Isaza, quien logró serenar a la familia y permitir la nueva aventura académica del pensador: el autodidactismo, que le caracterizó durante toda su vida; actitud que le lleva a ser reconocido en los más importantes ámbitos académicos del país como la Universidad Nacional, la Universidad Libre, la Universidad deAntioquía y la Universidad del Valle, sin títulos académicos y sólo con la legitimización de su investigación, su palabra y su saber.

La infancia y adolescencia de Estanislao Zuleta estuvieron determinadas por las relaciones de su familia, en especial del padre quien contaba con amigos muy fuertes

4 ZULETA, Estanislao, citado por MONTOYA, Ramiro. «Adolescencia de un memorioso». Op. Cit.,p. 8.

5 ZULETA, Estanislao. Conversaciones. Fundación Estanislao Zuleta, 1997, p.85.

6 ZULETA, José. «Semblanza». Op. Cit., p. 310. 
en el mundo intelectual del momento. Esto hizo que Fernando González, asumiera cierta responsabilidad en su formación intelectual. Desde los ocho años el filósofo lleva al niño Zuleta a pasear en la finca llamada «Otraparte», sitio de residencia y también del productividad académica de González; allí lo invitaba, no importando su corta edad, a decidir sobre problemas académicos e incluso personales; quería su opinión para encontrar posibilidades de solución a los mismos. Alberto Valencia, amigo del pensador, plantea al respecto: «El hecho ser tratado de igual a igual (por González), la confianza que depositaba en él y el alto grado de credibilidad que daba a sus opiniones, habrían influido significativamente en la construcción de un proyecto intelectual de pensar por sí mismo » ${ }^{7}$. La influencia de González no fue tan decisiva en la estructuración de sus opciones académicas; en opinión de Ramiro Montoya, otro de los amigos que compartió con él la adolescencia, reconoce que el filósofo de Envigado suscita la curiosidad intelectual y lo acerca a la lectura, además de la increíble fascinación producida al escucharlo y cita que algunos jóvenes con inclinaciones académicas incluidos Montoya y Zuleta, visitan al maestro tardes enteras para encontrar nuevas formas de interpretación y presentación de algunos textos. Estanislao Zuleta afirma al respecto: «Fernando González tenía una manera encantadora de hablar, con un lenguaje preciso, plástico, con una mímica abierta, con las manos hacia afuera. El padre que no conocí me lo hacía ver, aunque seguramente idealizado... yo frecuentaba otros amigos Gonzalo Arango, Carlos Castro Saavedra, Oscar Hernández y con mayor interés y una relación más larga, a Mario Arrubla.... ${ }^{8}$

El acercamiento paulatino al mundo cultural y académico de Estanislao Zuleta, lo llevó a labrar una ruta propia de aprendizaje y un camino diseñado a su medida y de acuerdo con sus dotes; al respecto Montoya afirma:

Yo creo que él buscó solo en la biblioteca de su padre una salida como reacción contra los valores de la familia y de la sociedad de Medellín, contra un mundo que él rechazó desde el principio, y esa reacción la canalizó a través de la lectura, pero por su propia inventiva, apoyado en los libros, en un proceso de asimilación, pasando de un autor a otro hasta llegar a los más complicados, con un menú que él mismo se fue diseñando» ${ }^{9}$.

7 VALENCIA, Alberto. En el principio la ética era. Cali: Editorial Universidad del Valle, 1993,p. 33.

8 ZULETA, Estanislao. Conversaciones con Estanislao Zuleta. Fundación Estanislao Zuleta, 1997, p. 105.

9 MONTOYA, Ramiro. «Adolescencia de un memorioso». Op. Cit., p. 9. 
Otra de las influencias tempranas sobre su vida y actitud intelectual la representó Fernando Isaza, tío político, ensayista y preocupado por la escritura correcta y la estilística, más cercano de la literatura y en sus obras intenta estudiar el estilo y la vida de sus autores. El tío regala a los catorce años a Estanislao La montaña mágica de Thomas Mann, autor muy importante en la construcción conceptual de su vida académica y de la cual realiza un magistral análisis que luego se publica en 1997 bajo el título de Thomas Mann, la montaña mágica y la llanura prosaica. Sus relaciones con el mundo intelectual y cultural aparecieron casi que en contravía con lo aprendido en la escuela. Las relaciones con la escuela primaria y básica fueron muy difíciles pero, como el mismo lo afirma, no con la educación, ni con los estudios, no con el saber y mucho menos con el pensamiento; el problema de Zuleta estuvo en relación con la práctica educativa que, desde su perspectiva, restringe el pensamiento, lo esquematiza, lo recorta y sobre todo la escuela básica hace que la aventura del mismo se convierta en mecanización y no en pensamiento.

Sus primeros acercamientos los tuvo con Thomas Mann y Dostoievski y luego la obra de Sigmund Freud y Carlos Marx. Su obra está inscrita no sólo en los apartes académicos del mismo sino en un arte de la existencia que lo lleva a constituirse como alternativa de construcción del mundo académico, curiosamente fuera del mismo, una ruptura con las habituales tradiciones de los académicos, un espacio de producción intelectual que desborda parámetros especializados y recuerda los viejos filósofos y pensadores más globales y cercanos al arte y a la sabiduría. Incluso el privilegio de lo oral sobre lo escrito y las posibilidades que ofrece la improvisación y el trabajo del pensamiento sobre sí mismo, pensar de otro modo y actuar de otro modo con lo pensado. Estas prácticas han de ser valoradas en el ámbito en el cual se producen sus ideas: no son elementos de orden circunstancial en la obra, sino que representan una serie de elementos constitutivos que describen su trabajo: «La presencia de un interlocutor como condición para la producción del discurso, la elaboración de su trabajo por fuera de los marcos institucionales, la tendencia a romper con cualquier forma de separación entre profesión y actividad vital, el compromiso con la vida cotidiana e inmediata, la consideración del pensamiento en las condiciones personales de su elaboración, la aspiración a integrar vida y pensamiento» ${ }^{10}$.

La relación con la Academia y con los académicos se hace inicialmente por fuera de la misma, formalizada e institucionalizada, en grupos de tertulia, publicaciones

${ }^{10}$ Ibíd., p 36. 
periódicas y luego como profesor invitado y conferencista de algunas Universidades. La década del 50 se convirtió en un período de tiempo en el cual se acercó a los grandes clásicos del pensamiento que definirían de manera clara su interés y su andamiaje conceptual lo cual permitió los diversos caminos de la crítica y la acción de su pensamiento. Inicialmente su encuentro con Platón y Descartes, luego con Freud, uno de sus amores intelectuales más fuertes. Con Heidegger y Sartre se acerca a los denominados existencialistas y en el año 53 lee a Marx. En este mismo año Estanislao Zuleta, una vez hecho miembro del partido comunista, realiza un viaje a Bucarest, donde se realiza el encuentro anual de juventudes comunistas; este viaje le sirve para conocer algunos libros de Sartre y algunos números de la revista Le temps. Se radica en Bogotá donde emprende una serie de estudios sobre historia económica de Colombia, tarea que le obliga a trabajar sistemáticamente a Hegel y la primera lectura de El Capital de Marx.

\section{Sobre la obra y el pensamiento educativo}

La obra de Estanislao Zuleta es muy variada en temáticas y también en intensidades. En palabras de Alberto Valenciatiene tres grandes características que se convierten en tres grandes obstáculos para entender su producción: «el hecho de que su obra no se corresponda a lo que convencionalmente puede denominarse como tal en un plano académico o universitario; la primacía otorgada a la exégesis de textos de autores y teorías sobre posibilidades de investigaciones y acceso al saber; y la presencia simultánea en diversos ámbitos del conocimiento». ${ }^{11}$

La primera premisa hace referencia que la obra no se planea intencionalmente en grandes libros. Se recoge de las diversas charlas, conferencias, entrevistas y tertulias realizadas por él y sus amigos. El centro de la sistematización de su obra está más en la oralidad que en la escritura; esta realidad le da un carácter diverso y determinante a la palabra y a su fuerza transformadora y vital. La conversación como posibilidad de interacción, todo interlocutor era válido para él, y en la interlocución se producía pensamiento, «para él la filosofía era conversación, diálogo vivo y directo con los otros y la lectura era apenas una preparación para la gran fiesta del diálogo» ${ }^{12}$. El segundo aspecto hace referencia a un trabajo de orden crítico-interpretativo y exegético sobre autores reconocidos en el ámbito de las Ciencias Humanas y la

11 VALENCIA, Alberto. En el principio la ética era. Op. Cit., p. 11.

12 OSPINA, William. «El arte de la conversación». En: Estanislao Zuleta 1935-1990. Ediciones la Rana y el Águila. UPTC, 1990, p. 84. 
Filosofía, para desde allí plantear las posibilidades permitidas por los mismos para realizar lecturas sobre la realidad y acercamientos al saber. Este tono dialéctico hace que la función de la razón esté en directa conexión con una lectura minuciosa, tranquila, documental, pero a la vez crítica; la tercera característica presentada en la obra está ligada a los grandes campos de saber de las humanidades en el mundo contemporáneo, dejando esbozada una especial relación con la teoría de la educación.

En algunas de sus reflexiones organizó una especie de ideario sobre las formas y las posibilidades de la educación para un proyecto cultural de País. En Zuleta, no existe un gran tratado sistemático sobre educación, pero a la vez, toda su obra,con su estilo propio, puede ser comprendida como una profunda experiencia de y sobre la educación. A parte de las vivencias con su retiro temprano de la escuela y su proceso de formación autodidacta, su pensamiento educativo hace énfasis en el enseñar a pensar; la educación filosófica; la formación para la convivencia y la democracia, aspectos que se describirán a profundidad en lo que resta del presente trabajo.

\section{Del autodidactismo o la opción autónoma por el conocimiento}

Un aspecto central de su pensamiento educativo es precisamente su experiencia de autodidactismo como forma de educación contemporánea, acerca del cual Zuleta afirma:

Sobre el autodidactismo no sé qué decir. Yo no concibo otra forma de estudiar. Eso puede ser un error. Un argumento a favor sería que para estudiar a fondo algo es necesario que corresponda a una cuestión vital que ha sido planteada por nuestra situación. En cambio, estudiar porque es un deber, en un programa que no tiene nada que ver con nuestra vida, puede que con mucha frecuencia, sea necesario, pero no es más que eso justamente: una necesidad» ${ }^{13}$.

En varios de sus escritos hace referencia al sitio de la educación en la sociedad y en especial, realiza una demoledora crítica a la educación en su forma escolar, es decir, a la pérdida de la perspectiva crítica, a la reiteración de los lugares comunes, a su institucionalización y empresarización. Estas condiciones no permitenlograr conocimiento en la medida en que el sujeto no piensa por sí mismo. Es aquí donde radica la opción de Zuleta, primero, en el contexto intelectual de su vida, y luego,

13 ZULETA, Estanislao. «Estanislao Zuleta: un gran encuentro con la inteligencia«. En: ZULETA, Estanislao. Conversaciones con Estanislao Zuleta. Op. Cit., p. 107. 
por una opción autónoma en el empeño por formar-se. En este sentido asume el camino de formación académica, no en el vacío o simplemente en una especie de «lectura piadosa» de los textos como afirmará en una crítica Gutiérrez Girardot ${ }^{14}$, sino en el camino de la autonomía, es decir, de la posibilidad de confrontar y optar por autores, problemáticas y prácticas que muchos de quienes han hecho su tránsito por la academia logran luego de ser certificados por sus «tutores».

Zuleta asume un caminoque no es necesariamente original y diferente en los grandes enunciados del saber y de la ciencia a los cuales accede; lo relevante en su proceso de constitución como intelectual es que logra aprovechar las condiciones posibilitadoras de un proceso de reflexión autónoma que sí se diferencia de los currículos tradicionales de formación de los profesionales y los intelectuales del país. Es decir, con todas la influencias, sugerencias y negaciones de sus maestros y pares académicos, lograr definir una ruta de formación que lo hace ingresar sin muchas formalidades en el método y la interpretación mediada por otros, es decir, se puede afirmar que Zuleta, especialmente, logra organizar una manera, una forma propia de acceso a los bienes de la cultura heredada de los grandes pensadores de los siglos XIX y XX. Puede decirse que el autodidactismo de Zuleta lo lleva a producir una estrategia de acercamiento y trabajo reflexivo sobre autores, problemáticas y contenidos. Por eso lo importante no está en los contenidos, sino en el tratamiento de los mismos. La apuesta de opción autónoma del conocimiento es una apuesta metodológica, es decir, de enfoque y estrategia: «[...] eligió la autoeducación [...] optó por un método distinto para pensar filosóficamente y compartir su reflexiones con sus compañeros y con la comunidad universitaria» ${ }^{15}$

\section{-Sobre el enseñar a pensar}

Uno de los aspectos centrales del pensamiento educativo de Zuleta es la posibilidad de enseñar a pensar, de pensar por sí mismo y de dejar la pasividad del pensamiento. Para Zuleta, el problema central de la educación formal en la actualidad, reside en que ella no se dedica a enseñar a pensar, pues reproduce formas, aspectos y hábitos que normalizan y controlan los estudiantes: «La educación tal como ella existe en la actualidad, reprime el pensamiento, transmite datos, conocimientos, saberes y resultados de procesos que otros pensaron, pero no enseña ni permite pensar. A

14 GUTIERREZGIRARDOT, Rafael. «Figuras imaginarias». En: RevistaAquelarre. Universidad del Tolima. \#8. Septiembre de 2005, p. 45-46.

15 PACHÓN SOTO, Damián. « Estanislao Zuleta y la educación filosófica». En: PACHÓN SOTO, Damián. Estudios sobre pensamiento colombiano Vol I., p. 190. 
ello se debe que el estudiante adquiere un respeto por el maestro y la educación que procede simplemente de la intimidación ${ }^{16}$. De esta manera, para el caso colombiano, reconoce cómo los procesos educativos formales han estado signados por diversos posturas pedagógicas que han hecho del mismo un instrumento regulador del sistema a través del modelo empresarial: han operativizado en exceso la labor del maestro y el sitio del estudiante, en consecuencia, el bachillerato se convirtió en «la cosa más vaga, confusa y profusa». ${ }^{17}$ Tanto estudiantes como profesores se ahogan en este mar de conocimientos con muy poca profundidad y reproducen acríticamente el sistema que requiere personas sumisas, confundidas, flexibles y poco pensantes.

Zuleta emprende una profunda crítica a la educación pensada como empresa con lascaracterísticas de un modelo que ofrece gran cantidad de información con economía de tiempos y de esfuerzos. Critica la forma como los medios audiovisuales y los adelantos tecnológicos que han ingresado al mundo de la educación y la escuela para convertir los procesos de enseñanza y aprendizaje en una especie máquina ahorradora de tiempo, de esfuerzo que hace menos laborioso y costoso el proceso. El reclamo deZuleta está en que los sistemas educativos, y en especial el colombiano, confundeneducación con información; al respecto afirma: «La ideología de la información ha producido una revolución en el campo educativo que es prácticamente una peste. Es allí donde queda más radicalmente reprimido el pensamiento como actividad $\gg^{18}$.

En contra de esta situación, propone que la educación ha de tener siempre una perspectiva filosófica pues en la educación contemporánea además de enseñar resultados sin tener en cuenta los procesos del conocimiento, el gran problema es que se enseña sin filosofía, es decir, sin la posibilidad de que los estudiantes pregunten, que piensen las cosas, que asuman la contradicción y la dialéctica como herramienta del pensamiento. Se requiere una educación filosófica en todas las áreas y unas áreas del conocimiento posibilitadoras de la aventura del pensar y el ejercicio de la autonomía. Este tipo educación filosófica tiene su sustento en el racionalismo ilustrado: en el corazón mismo del pensamiento moderno de inspiración kantiana. La educación se debe orientar por la idea de pensar por sí mismo, de valerse del propio entendimiento y de arriesgarse. No se debe considerar ninguna verdad como dogma,

${ }^{16}$ ZULETA, Estanislao. Educación y democracia un campo de combate. Bogotá: Fundación Estanislao Zuleta y Corporación Tercer Milenio, 1995, p. 19.

${ }^{17}$ Ibíd., p 15.

${ }^{18}$ Ibíd., p. 23. 
como infalible. Para lograr pensar por símismo se tiene que ser capaz de colocarse en el lugar del otro, es decir, tener la capacidad de discutir y dialogar con otros puntos de vista, y por último, ser consecuentes, ser coherentes en cuanto a corregir y actuar cuando nuestros puntos de vista están errados, es decir, aceptar y transformar.

\section{La educación filosófica y la educación con filosofía}

Zuleta no concibe la educación sin filosofía. Las características de una educación filosófica residen en los siguientes componentes: pensar y no solamente aprender ciegamente; eliminar el dogma en educación; reconocer la angustia;apropiar la felicidad y la liberación del pensamiento; situar el lugar de la Filosofía como combativa y combatiente; la formación democrática como resultado de la educación filosófica.

Zuleta privilegia una educación filosófica para pensar y no para aprender ciega y mecánicamente. Esta distinción se realiza en función de examinar la actividad y trabajo del pensamiento frente a la simple adquisición de conocimientos de orden irreflexivo denominado por Zuleta «aprendizaje». En otras palabras, el pensamiento trabaja, se ejercita y para ello utiliza diversas herramientas y materiales que le permiten «ubicarse en un campo de fuerzas en que se enfrentan las ideas que tratan de irrumpir y las construcciones científico- ideológicas determinan lo comunicable y por lo tanto lo pensable» ${ }^{19}$.

El aprendizaje considerado simplemente, en el sentido restrictivo, como la adquisiciónde los resultados anteriores al trabajo del pensamiento y de la investigación, es decir, en una concepción puramente cronológica, como mera acumulación de conocimientos, no es educativo. Es necesario aclarar que el problema no es temporal en el sentido de agregar conocimientos, sino un problema lógico de comprensión y explicación, un proceso dado en la polémica y el acompañamiento:

... que el pensamiento no es un hecho cronológico, sino lógico; que el saber a que conduce es nuevo, no porque nunca se haya producido en la historia, sino porque surge del descoyuntamiento crítico de las nociones, lo valores y los prejuicios que lo prohibían. Hay que subrayar que si el conocimiento es aprendizaje de un saber y el pensamiento es producción-reproducción de un saber, esa diferencia no se refiere a la existencia o inexistencia previa del saber, sino a la forma, a la significación y a las consecuencias de los dos $\operatorname{procesos}^{20}$.

${ }^{19}$ Ibid., p. 23.

${ }^{20}$ Ibíd., p. 24. 
De esta manera la educación formal acostumbrada a centrar su mirada en el «aprendizaje», sobre todo desde la inclusión del modelo de la tecnología educativa en Colombia, requiere un viraje que le permita generar las condiciones mínimas para que estudiantes, y sobre todo los profesores,ejerciten y trabajen con el pensamiento; pues es posible conocer e incluso enseñar cualquier área del saber sin pensarlas. Se mecaniza al niño y al joven de tal manera que su disposición para ser pensador e investigador aparece aniquilada. Es así como la educación, sobre todo la formal, se piensa como una industria y los productos de la misma, pues «ofrece una cantidad cada vez mayor de información en el mínimo tiempo y con el mínimo esfuerzo ${ }^{21}$; en esta perspectiva se lleva la educación a los mismos niveles e indicadoresdel modelo empresarial de la calidad total, confundiendo, en palabras de Zuleta, educación con información.

Este tipo de desviación al aprendizaje se observa cotidianamente en las aulas escolares y se refuerza con los procedimientos de evaluación y la consolidación de modelos pedagógicos instalados desde la psicología conductual que mecaniza el aprendizaje de los estudiantes. Zuleta es enfático en recordar que una de las grandes fallas de los maestros consiste en exigir recitaciones sin sentido, sin pasar del aprendizaje repetitivo a la actividad del pensamiento, y en no considerar a los estudiantes como inteligentes o interlocutores válidos para comprender y examinar conceptos.

Para atravesar el umbral del aprendizaje repetitivo hacia el pensar y a favor de la actividad del pensamiento, Zuleta ubica a la Filosofía como principal herramienta conceptual para lograr procesos educativos que permitan pensar culturalmente. A este respecto, la Filosofía debe subsumir toda la educación en sus prácticas y en sus discursos, todas las áreas del saber se deben enseñar con filosofía, incluso la Filosofía misma en término del ejercicio del pensar y de su cercanía con la sabiduría:

Entiendo por filosofía la posibilidad de pensar las cosas, de hacer preguntas, de ver contradicciones. Asumo el concepto de filosofía en un sentido muy amplio, en el sentido griego de amor a la sabiduría. Es un filósofo el hombre que quiere saber; el hombre que aspira a que el saber sea la realización de su ser; el hombre que quiere saber por qué hace algo, para qué lo hace, para quien lo hace; el hombre que tiene una exigencia de autonomía. El hombre que está inscrito en una búsqueda de universalidad es también un filósofo, así como aquel que quiere ser consecuente con los resultados de su investigación ${ }^{22}$.

21 Ibid., p. 24.

${ }^{22}$ Ibíd., p 26. 
La educación filosófica se puede ubicar en la escuela racionalista pero también se articula con condiciones existenciales y sociales. Los criterios que asume Zuleta para su definición son los mismos que plantea Kant refiriéndose a la modernidad, la ilustración y el mismo racionalismo y se pueden comprender como actitudes que permiten a los sujetos actuar de determinada manera. En primera instancia pensar por sí mismo, que exige la valentía de renunciar a las órdenes de alguna autoridad, por el encargo de adoptar «verdades» y valores sin mediar la elaboración propia, sinevaluar el valor argumentativo de legitimidad y de justicia. En segundo término, poder ubicarse en el lugar del otro, en sus puntos vista, en sus maneras de elaborar y actuar; y por último, ser consecuentes con los resultados de los procesos propios de investigación, es decir, aceptar los errores y corregir o afirmar lo que se considera pertinente. En una educación en esta dirección «se dificultaría seguramente crear buenos funcionarios, pero probablemente se construiría la posibilidad de formar gentes que luchen por un tipo de sociedad en la que valga la pena vivir y valga la pena estudiar ${ }^{23}$.Por eso es claro que Zuleta deja para la escuela colombiana y toda la educación formal un legado que exigiría a los diseñadores de políticas educativas romper el modelo orientado únicamente al aprendizaje repetitivo y producir condiciones que permitan a los niños y a los jóvenes pensar y ejercitar el pensamiento.

El segundo aspecto de los planteamientos educativos es la superación del dogma. En Zuleta, dogma es «toda convicción que ha llegado a ser para quien la posee una referencia de su propia identidad ${ }^{24}$ y por su inventada importancia no puede ser perdida; en este sentido afirma, que en principio, todos somos dogmáticos o, dicho en otras palabras, buscamos el dogma para estar seguros, para caminar firmemente, para tener soportes que nos eviten la incertidumbre y la angustia, es decir, la aventura del pensar. Desde que los niños llegan al mundo se encuentran con el dogmatismo, con transmisiones culturales que los hacen ser y actuar de determinadas maneras en la búsqueda de seguridades fuera de sí mismos. La tendencia a adjudicarle un sitio de privilegio a las propias costumbres y creencias frente a otras opciones u opiniones, hace que el dogmatismo se instale y se busque. La educación en su estilo formal e informal cumple un papel clave para la instauración del mismo, es decir, se construye una manera dogmática de ver, sentir y estar en el mundo.

Con Zuleta se puede afirmar que la educación formal quebusca verdades y formas irrefutables para pensar y actuar es una educación que permite, busca, define y consolida el dogmatismo. En este sentido la escuela se convierte en aquella máquina

23 Ibíd., p27.

${ }^{24}$ ZULETA, Estanislao. «Tribulación y felicidad del pensamiento».Op. Cit., p. 19. 
o institución de orden disciplinar que va constituyendo en su interior verdades asumidas acríticamente y que, a su vez, son defendidas y protegidas por lo miembros activos de la misma. Se anula así la posibilidad del debate y de la oposición y se culminade aquellas maneras de discutir que llegan al extremo de laintolerancia. Algunas de las pretensiones, válidas para los otros, se niegan: el dogmatismo no sólo se traduce en posturas radicales, opuestas y enfrentadas, sino que a su vez, en la educación se posibilita el falso respeto por las diferencias y el «aguante» por los otros y sus ideas.

En Zuleta es claro que la lucha contra el dogmatismo es muy difícil pues representa la «manera como se articulan las formas de identidad, los deseos y las representaciones colectivas ${ }^{25}$, con su asidero en mitos o palabras fundantes, en sitios de origen y esencialidad. Y es en lo fundante del dogmatismo donde radica su naturalización, pues comunidades y sujetos buscan elementos fundadores que permitan tranquilizar sus formas y maneras de vivir. De aquí que al pensamiento, a su ejercicio y a su enseñanza le es muy importante evidenciar y sobre todo «desarticular un sistema de supuestas evidencias y de interpretaciones previas» ${ }^{26}$, no obstante, de igual manera, debe tener la afirmación y la potencia de producir nuevas relaciones y formas de subjetivación. Propiamente no sepuede enseñar a romper con la imagen dogmática, afirmaría Zuleta, pero la función de la escuela sí puede transformarse y sobre todo desestructurarse, pues el problema no consistiría simplemente en enseñar, sino en producir condiciones propicias de constitución de crisis desarticuladoras y de posibilidades de reconstrucción continua, es decir, un ejercicio del pensamiento sobre sí mismo y sobre las prácticas y posibilidades de existencia. En esta perspectiva, el pensamiento es acción y praxis comprometida, está situado en el ser capaz de atreverse a pensar y pensar por símismo como lo afirma Kant en el texto Respuesta a la pregunta ¿qué es la ilustración? La situación reside en ubicar este ideal en el centro del proceso educativo, es decir, en un estado democrático; cualquier relación de saber debe estar definida por el pensamiento,no por el dogmatismo, esta finalidad, sin embargo, se convierte en ideal la mayoría de las veces irrealizable, es utópico, pero es una exigencia en de vida práctica para la educación y en orientación de proyectos sociales.

El tercer aspecto del pensamiento educativo de Estanislao Zuleta, inspirado en J.P. Sartre, reside en que la educación sólo se encuentraen la soledad, la angustia y la liberación del pensamiento. Es claro que el camino del pensamiento y del pensar no es un privilegio de seres superiores o superdotados, pero que sí es necesario lograr

25 Ibíd., p. 21.

26 Ibíd., p. 22. 
condiciones para la curiosidad, el pensamiento y la expresión del mismo, que se ofrece en la soledad: en su inquietud interior. El niño comienza la exploración del mundo y los demás se convierten en obstáculos para su realización. El niño y el joven en la soledad formulan las grandes preguntas que les interesan;con el asombro que les producen; no requieren respuestas ilustradas, ni informaciones, requieren posibilidades de consolidación de las mismas y tiempo para expresarlas. Este es un proceso de autoconocimiento: no se les puede ayudar. El niño y el joven buscan situarse y tomar una postura respecto de la diferencia, es decir, es «El niño investiga con todas sus experiencias corporales, con sus temores, con sus deseos y con sus fantasmas ${ }^{27}$. Estas son las condiciones de las investigaciones originarias y, en adelante, serán «las tribulaciones del pensamiento» que van a perseguir y a complicar al niño y al joven en su pensamiento, en su formación y en el camino de la educación. Estas son precisamente las condiciones que la escuela y la educación formal olvidan. De aquí que la nostalgia, la transgresión, la soledad y la angustia serán situaciones iniciales de incentivación del pensamiento,remplazadas en la educación tradicional por certezas y protección.

En la escuela mecanizada y tecnologizada del y para el aprendizaje instrumental, no existen los espacios ni los tiempos para la interioridad, la soledad y las preguntas que niños y jóvenes puedan problematizar desde su experiencia vital frente al pensamiento. Es aquí donde aparece la pregunta acerca de si la escuela e incluso la universidad, en las que diariamente se acuden a las aulas, tienen la posibilidad de transformase y generar este tipo de condiciones que permitan la ruptura de concepciones y posibiliten desarrollos autónomos, diferenciados y potencializadores. O en otros términos, sería pensar de manera diversa los procesos de escolarización e interacción con el conocimiento.

El cuarto aspecto para la educación del pensamiento es la felicidad, la autoafirmación y el sentimiento de liberación, pues «si el pensamiento fuera solamente duelo, soledad y angustia seguramente no existiría $»^{28}$. En este sentido Zuleta recuerda el descrédito de la felicidad, de sus acepciones y de sus prácticas, generalmente relacionadas con ciertas vinculaciones a ideales religiosos, políticos o eróticos que se convierten en absolutos, es decir, que la transforman en un espacio de la ilusión y sobre todo del engaño. En Zuleta, la felicidad se genera a través de una cualidad cuyo punto de acción es el cambio, y la resignificación del andamiaje de las posibilidades e imposibilidades, a las cuales los sujetos están continuamente avocados, en otras

27 Ibid., p. 33.

28 Ibíd., p. 33. 
palabras, la felicidad es una afección, un efecto puesto en juego en la medida en que nuestras condiciones vitales se oponen y se sintetizan armónicamente.

Aparte de ser una cualidad particular y específica, la felicidad, funciona en dos sentidos diversos y diametralmente opuestos: la creación y fortalecimiento de un orden normativoy en este sentido afirma, «consiste en un acceso a un orden, a un sistema de valores, a un conjunto de referencias simbólicas que ofrezca una mayor continuidad, previsibilidad y funcionalidad, a partir de una dispersión angustiada, de una identidad demasiado lábil y vulnerable. Es el acceso a una construcción normativa posibilitante, lo cual sólo resulta paradójico si permanecemos en el prejuicio, tan difundido hoy, de que toda construcción normativa es limitadora de no se sabe qué libertad $\gg^{29}$. La la posibilidad de realizar rupturas, fisuras y ejercicios de derrumbamiento de esquemas, moldes y estructuras ofrece felicidad:

...la felicidad de ver surgir en sí mismo deseos ignorados y posibilidades desconocidas, que no eran compatibles con alguna imagen oficial, con las expectativas de algunos textos privilegiados. Se desata entonces la risa, la risa que procede del sentimiento tardío, del descubrimiento retrospectivo de que estábamos haciendo un largo y tenaz esfuerzo que se ha vuelto inútil; la energía de ese esfuerzo, liberada, se desborda incontenible en la risa. $\mathrm{O}$ bien viene a nosotros como lágrimas de alegría por el reconocimiento de que lo que ahora logramos, es algo que sin saber se había deseado siempre, desde el comienzo había estado allí, insistente frustrado y oculto ${ }^{30}$.

De alguna menara bajo la inspiración de la filosofía de Nietzsche, es en este doble juego de control y liberación se expresa la felicidad de la autoafirmación, aparecen las potencialidades, el pensamiento y la posibilidad de una vida que no sólo reproduzca modelos y sistemas, sino que el individuo pueda a su vez construir unas condiciones básicas de convivencia, liberación y afirmación de la vida. Esta invitación de Zuleta coloca en un sitio bastante complicado a la educación formal, pues la pregunta que surge es ¿Cómo lograr que en la escuela, históricamente tan disciplinaria, tradicional y mecanizada puedan existir espacios para la liberación y afirmación de los sujetos? ¿Cuál puede ser el sitio del maestro allí en esta responsabilidad formativa?

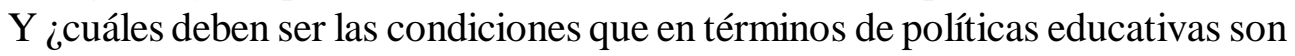
necesarias para lograr estos resultados en los proceso educativos? Que el pensamiento libere no debe ser solamente una ilusión o un engaño de la educación,

29 Ibíd., p. 34.

30 Ibíd., p. 34. 
es necesario que esta acción del pensamiento comience a habitar los espacios escolares y los sujetos protagonistas del mismo.

\section{LAS CONDICIONES EDUCATIVAS DE LA DEMOCRACIA}

El último aspecto que se aborda del pensamiento educativo de Zuleta, presenta las relaciones de la educación con la democracia, preocupación constante del filósofo y tema de trabajo teórico y práctico a lo largo de su vida. Estas relaciones se presentan en muchas de sus conferencias y escritos, las cuales se concentran en dos fundamentalmente: un texto publicado en 1988 en la Revista Foro denominado «Democracia y participación» ${ }^{31}$ y otro publicado por la Universidad Pedagógica y Tecnológica de Colombia y en un texto complicación de varios ensayos sobre el pensamiento de Zuleta titulado «La participación democrática y su relación con la educación ${ }^{32}$.

La concepción de democracia en Zuleta es retomada de la cultura griega: reconoce que el ámbito democrático griego permite la creación de la ciencia, pues las discusiones, disputas y diálogos establecidos sin dogmas y con la posibilidad de disentir y estar en desacuerdo con los otros, lo posibilitó (aunque critica también, lo limitado de su ejercicio). La demostración racional y el proceso por el cual se accede a la misma harán posible la controversia y la necesidad de comprobar y no de imponer la opinión. De esta manera, la lógica y la ciencia nacen del ambiente democrático y de la posibilidad de la argumentación. Para Zuleta «la ciencia es democrática, porque la democracia es su origen y, por eso, la idea de ciencias ocultas es una contradicción en los términos, como el hielo frito. La ciencia es abierta; la ciencia es accesible; el proceso puede ser largo, pero no está en manos de ninguna casta cerrada. Es importante ver que en esa necesidad de discutir genera la lógica. La lógica termina por ser la matriz de todas las ciencias» ${ }^{33}$.

De otra parte, Zuleta afirma que la democracia tiene un alto componente de tragedia: la carencia de un referente absoluto, un dios, produce angustia pues cada persona busca sus creencias, sus acciones y la orientación para conducir la vida y decidir sobre las actuaciones, por eso «la democracia no es un deseo fácil de tener; es muy

31 ZULETA, Estanislao. «Democracia y participación». En:Violencia, democracia y derechos humanos. Bogotá: Ediciones Altamir, 1991.

32 ZULETA, Estanislao. «La participación democrática y su relación con la educación». En: Estanislao Zuleta 1935-1990. Tunja: Ediciones la Rana y el Águila UPTC, 1990.

33 Ibíd., p. 26. 
fácil elogiarla, pero es muy difícil aceptarla en el fondo, porque la democracia es angustia, es aceptación de la angustia. Porque es angustiante tener que decidir por sí mismo, ya que se puede entrar en conflicto al escoger entre dos cosas deseadas e incompatibles: esa es la tragedia» ${ }^{34}$. Otro elemento para definir y comprender la democracia hace referencia a la modestia, en el sentido de reconocer «que la pluralidad de pensamientos, opiniones, convicciones, y visiones enriquecedoras; que la mía no es segura porque su confrontación con otras puede hacérmela cambiar o, bien, enriquecérmela; que la verdad no es la que yo tengo en la mano; que la verdad sale del debate, del conflicto ${ }^{35}$. Y en el reconocimiento de la modestia Zuleta arriesga otra de las características fundamentales de la democracia y es el respeto. El respeto tiene que ver con el reconocimiento y la valoración del pensamiento del otro: «discutirlo, debatir con él sin agredirlo, sin violentarlo, sin ofenderlo, sin intimidarlo» ${ }^{36}$. El respeto no debe ser entendido en el sentido laxo del término, de permitir que el otro piense lo que quiera sin argumentos; donde los diálogos se convierten en monólogos respetados en una cómplice mediocridad.

Después reconocer características de la democracia desde la cultura y la política griega, con respecto a las condiciones modernas, Zuleta plantea tres vías de desarrollo de la misma: las condiciones sociales de posibilidad,de la igualdad y de la racionalidad. En cuanto a las condiciones socioeconómicas y culturales para la democracia, no basta la filosofía liberalde derechos humanos, convertidos en la bandera contemporánea, aunque se asume que éste es un requisito mínimo de ejercicio democrático. Zuleta critica la postura simplemente liberal: expresa que unos mínimos sin posibilidades no son nada, o mejor no bastan los derechos ideales y no reales. Las condiciones para la democracia y el sentido de la igualdad se reflejan en una búsqueda de condiciones económicas y culturales, en un cierto camino de realización concreta de las normas y los derechos, «es casi una burla para una población decir que todos los ciudadanos son iguales y libres ante la ley, si no lo son ante la vida ${ }^{37}$. Pero las condiciones y la igualdad no las decreta nadie, se luchan y se consiguen. Así, la democracia y su ejercicio requieren una acción de participación; el ejercicio democrático está atravesado por la racionalidad, y a la vez, la racionalidad es la clave de la democracia, pues el diálogo se da con iguales, la ciencia se produce con iguales y sólo en la participación aparece la consolidación de la sociedad. Con estas premisas Zuleta aborda una pregunta central en la relación con lo educativo y

34 Ibíd., p. 29.

35 Ibíd., p. 32.

36 Ibíd., p. 33.

37 ZULETA, Estanislao. «Democracia y participación», Op. Cit., p. 227. 
es ¿Cómo es posible una educación democrática? ¿Cuáles son las herramientas tanto conceptuales como prácticas para realizarla en condiciones adversas como las que Colombia vive, finalizando el siglo XX y comenzado el XXI?

\section{A manera de conclusión}

En las discusiones contemporáneas la educación se ha convertido en un verdadero campo de combate, un sitio donde diferentes fuerzas batallan para orientar la constitución de un tipo particular de sujetos. Para el caso colombiano, a partir de la segunda mitad del siglo XX la educación en general, y escuela en particular, asumen el modelo de la planificación y el desarrollo económico.Esta opción produce en las prácticas concretas de formación efectos como la implementación del modelo pedagógico de la tecnología educativa y la mirada de la educación como empresa productiva, olvidando y relegando otros ámbitos de la formación básica y superior. En este sentido el trabajo intelectual de Estanislao Zuleta, es un campo fértil para estudios sobre la educación, lo educativo y los proyectos de construcción de nacionalidad para Colombia.

Zuleta quien vive y sufre la educación formal instrumentalizada y el aprendizaje centrado en la repetición y la memoria, asume una profunda y demoledora crítica contra las formas institucionalizadas de la educación, resaltando en ella la superficialidad y la esquematización del modelo, reduciendo a los sujetos a sumisos repetidores y legitimadores de los intereses del capitalismo contemporáneo. Es decir, la educación formal reproduce y contribuye a la división social del trabajo excluyente de la formación culturaly ubica su utilidad en la eficiencia y en la eficacia del esquema productivo.

Una de las primeras acciones críticas de Zuleta consistió en la opción de abandonar la escuela a temprana edad y realizar una opción autónoma por el conocimiento, no en el sentido de desconocerlo, sino en el de la posibilidad de generar su propia ruta de formación. Esta práctica remite a las posibilidades de apuestas por formas de auto-aprendizaje y autoeducación, realizadas por modelos y propuestas contemporáneas de pedagogía.

La educación ha de ser planeada y ejercitada en los escenarios formales y no formales para el pensamiento y no simplemente para la reproducción de algunas certezas pensadas por otros y mediadas por el maestro. La educación debe desprenderse de dogmas y verdades absolutas, pues los saberes deben ofrecer la posibilidad de 
ser discutidos, contextualizados y reorganizados. La educación ha de asumir la filosofía, en otras palabras, debe ser filosófica, en todas las áreas del saber incluida la misma Filosofía, pues no puede existir una educación para el pensamiento sin que haya actitud de filosofar.

La formación del pensamiento en Zuleta tiene cuatro componentes básicos para su ejercicio: la ruptura con los dogmas en cuanto a la posibilitar pensar y no solamente aprender cúmulos de conocimientos; descubrir la felicidad de la autoafirmación a través de la soledad y la angustia como potenciadores del pensamiento; y asumir desde el pensamiento la lucha por construir la democracia, es decir, buscar las posibilidades socialespara la igualdad y la racionalidad. Considera Zuleta que la educación está estrechamente relacionada con la formación y el ejercicio democrático y ciudadano.

\section{Bibliografía}

MONTOYA, Ramiro. «Adolescencia de un memorioso». En: Al Margen. \#23. Septiembre de 2007. Bogotá.

VALENCIA, Alberto. En el principio la ética era. Cali: Editorial Universidad del Valle, 1996.

---_ Estanislao Zuleta o la Voluntad de Comprender. Medellín: Hombre Nuevo Editores, 2005.

- - - Estanislao Zuleta». En:Pensamiento colombiano del siglo XX. Bogotá: Instituto Pensar. Universidad Javeriana, 2007.

ZULETA, Estanislao. «Marxismo y psicoanálisis». En: La Filosofía en Colombia. Procultura, 1986.

---_Arte y Filosofía. Medellín: Editorial Percepción, 1985.

-_-_Ensayos sobre Marx. Medellín: Editorial Percepción, 1987.

- - - «La participación democrática y su relación con la educación». En:Estanislao Zuleta 1935-1990. Ediciones la rana y eláguila. UPTC. 1990.

--- Colombia: Violencia, democracia y derechos humanos. Bogotá: Altamir Ediciones, 1991.

--- Educación y democracia un campo de combate. Bogotá: Fundación 
Estanislao Zuleta y Corporación Tercer Milenio, 1995.

- - - Lógica y Crítica. Universidad del Valle, 1996.

-- - Conversaciones con Estanislao Zuleta. Cali: Fundación Estanislao Zuleta, 1997.

--- Comentarios a Así hablaba Zaratustra de F. Nietzsche. Hombre Nuevo editores, 2006.

- - - «Tribulación y felicidad del pensamiento». En: ZULETAEstanislao. Elogio de la dificultad y otros ensayos. Décima edición. Medellín: Hombre Nuevo Editores, 2007.

--- Elogio de la dificultad y otros ensayos. Medellín: Hombre Nuevo Editores. Fundación Estanislao Zuleta, 2007.

ZULETA, José. «Semblanza». En: ZULETA, Estanislao Colombia: Violencia, democracia y derechos humanos. Bogotá: Altamir Ediciones, 1991. 